\title{
Incidence and risk factors of persistent low back pain following posterior decompression and instrumented fusion for lumbar disk herniation
}

This article was published in the following Dove Press journal:

Journal of Pain Research

4 May 2017

Number of times this article has been viewed

\author{
Hui Wang' \\ Tao Wang' \\ Qian Wang ${ }^{2}$ \\ Wenyuan Ding' \\ 'Department of Spine Surgery, \\ ${ }^{2}$ Financial Statistics Department, The \\ Third Hospital of Hebei Medical \\ University, Shijiazhuang, People's \\ Republic of China
}

Introduction: The aim of this study was to explore the incidence and risk factors of persistent low back pain (PLBP) following posterior decompression and instrumented fusion for lumbar disk herniation and to provide references in decision-making and surgical planning for both spinal surgeons and surgically treated patients.

Patients and methods: By retrieving the medical records from January 2013 to December 2016, 221 patients were retrospectively reviewed. Patients were classified as having PLBP if numeric rating scale (NRS) scores were $>50$ at all postoperative follow-up time points ( 3 months, 6 months, and 12 months). According to the occurrence of PLBP, patients were divided into two groups: PLBP group and non (N)-PLBP group. To investigate risk values for PLBP, the following three categorized factors were analyzed statistically. Patient characteristics: age, gender, body mass index (BMI), preoperative low back pain, comorbidity, smoking, and drinking. Surgical variables: surgical strategy, surgical segment, the number of fusion levels, surgery time, blood loss, and size of incision. Radiographic parameters: preoperative lumbar lordosis (LL), correction of LL at immediate postoperation, Modic changes, and preoperative paraspinal muscle degeneration.

Results: PLBP was detected in 16 patients and were enrolled into the PLBP group. There was no difference between the two groups in age, gender, BMI, comorbidity, smoking, and drinking. The preoperative low back pain was more severe in the PLBP group than that in the N-PLBP group. There was no difference in surgery time, blood loss, surgical strategy, number of fusion levels, and the size of incision. Surgery segment at $\mathrm{L}_{5}-\mathrm{S}_{1}$ was more prevalent in the PLBP group than that in the N-PLBP group, and there was no difference in preoperative LL, correction of LL, preoperative lumbar mobility, and Modic changes. The fatty infiltration rate (FIR) was larger in the PLBP group than that in the N-PLBP group. Multivariate logistic regression model revealed that preoperative low back pain (NRS $>35$ ), surgery segment at $\mathrm{L}_{5}-\mathrm{S}_{1}$, and FIR $>15 \%$ were independently associated with PLBP.

Conclusion: The incidence of PLBP following posterior decompression and instrumented fusion for lumbar disk herniation is $7.2 \%$, and the risk factors include preoperative low back pain, surgery segment at $\mathrm{L}_{5}-\mathrm{S}_{1}$, and preoperative paraspinal muscle degeneration.

Keywords: persistent low back pain, posterior decompression and instrumented fusion, lumbar disk herniation.

\section{Introduction}

Posterior decompression and instrumented fusion, including posterior lumbar interbody fusion (PLIF) and transforaminal lumbar interbody fusion (TLIF), is supposed to be the most commonly used surgical strategy for lumbar disk herniation. ${ }^{1-3}$ Fusion is performed at the level of the intervertebral joint, and the anterior column is reconstructed as the load-bearing structures are restored, which create a biomechanically
Correspondence: Wenyuan Ding Department of Spine Surgery, The Third Hospital of Hebei Medical University, I39 Ziqiang Road, Shijiazhuang 05005I, People's Republic of China Email dingwenyuan20I2@I26.com 
superior environment for bone fusion. ${ }^{4,5}$ In general, the intervertebral bone fusion rates of PLIF and TLIF procedures were reported to reach $100 \% .{ }^{6}$ Most of the patients get lower limb pain relief following lumbar nerve decompression and instrumented fusion. In a series of 45 patients with a mean follow-up period of 18 years, Baeesa et $\mathrm{al}^{7}$ demonstrated that PLIF is acceptable with good long-term outcomes and excellent fusion rates. Abd El-Kader ${ }^{8}$ suggested that TLIF is an effective option for the treatment of selected cases of recurrent lumbar disk herniation with good clinical and radiological outcomes. However, postoperative onset of low back pain or recurrent back pain is common. In a systematic literature review, the short-term (6-24 months) and long-term proportion ( $>24$ months) of recurrent low back pain after primary single-level lumbar discectomy ranged from $3 \%$ to $34 \%$ and $5 \%$ to $36 \%$, respectively. ${ }^{9}$ The persistent low back pain (PLBP) may increase the incidence of postoperative complications, as well as decrease the patients' satisfaction, and thus need to be paid specific attention.

Previous studies mainly focused on the risk factors and management for postoperative low back pain after discectomy. ${ }^{10,11}$ Carragee et $\mathrm{l}^{12}$ reported an $11 \%$ incidence of persistent back or leg pain after limited discectomy and a $23 \%$ incidence of persistent back or leg pain after aggressive discectomy. Schoeggl et $\mathrm{al}^{13}$ demonstrated that $24 \%$ of patients experienced persistent or recurrent pain at a mean follow-up of 7.3 years. The spinal pedicle screw-rod fixation system used in TLIF and PLIF can provide immediate and long-term stability, promote interbody fusion, and maintain a potential advantage in reducing postoperative low back pain. To the best of our knowledge, whether the instrumentation can decrease the incidence of postoperative low back pain and what are the risk factors of PLBP following instrumentation lack evidence. Therefore, the purpose of this study is to explore the incidence and risk factors of PLBP following posterior decompression and instrumented fusion for lumbar disk herniation and to provide references in decision-making and surgical planning for both spinal surgeons and surgically treated patients.

\section{Patients and methods Subjects}

This is a retrospective study and was approved by the institutional review board of the Third Hospital of Hebei Medical University before data collection and analysis. The inclusion criteria were 1) lumbar disk herniation (LDH), received surgical treatment of PLIF or TLIF and 2) regular followup in outpatient clinic at 3-, 6-, 12-month postoperation, the low back pain was evaluated at every follow-up time point. Patients were excluded if they met any of the following criteria: 1) spinal deformity of scoliosis or kyphosis as the primary indication for surgery; 2) surgery secondary to infection, pseudarthrosis, inflammation, trauma, and tumor; 3) presence of schizophrenia, cognitive dysfunction, or other psychotic disorders; and 4) surgery under workman's compensation claim or medical disputes.

By retrieving the medical records from January 2013 to December 2016, 221 patients who met both the inclusion and exclusion criteria were retrospectively reviewed and all of them provided written informed consent for the use of their data. Of them, 130 were females and 91 were males, with a mean age of $57.2 \pm 7.2$ years (ranging from 37 to 69 years). A total of 143 cases undertook PLIF (125 of them received one-level PLIF and 18 patients received two-level PLIF), and 78 cases undertook TLIF (56 of them received one-level TLIF and 22 patients received two-level TLIF).

\section{Clinical and radiological evaluation}

The numeric rating scale (NRS) was used to assess pain on a scale ranging from 0 to 100 , where 0 represented "no pain" and 100 represented "extreme pain."14 Lumbar lordosis (LL) was measured from $\mathrm{T} 12$ inferior end plate to $\mathrm{S} 1$ superior end plate by the Cobb method on lateral X-ray (Figure 1). Lumbar mobility was calculated as the change in lumbar curvature on flexion and extension lateral radiographs (Figure 2). The crosssectional areas (CSA) of paraspinal muscles (multifidus and erector spinae) were obtained from axial T2-weighted images using magnetic resonance imaging (MRI), which was superior in distinguishing muscle from fat, at the lower margin of L3 and L5 vertebrae. Fatty infiltration rate (FIR) of paraspinal muscles was calculated by subtracting the muscle without the fat value from the total muscle value, and the images were adjusted with the image processing software (Image J, version 1.48, USA; Figure 3). Data measurements were performed three times with $200 \%$ magnification for accuracy by the first and second authors independently, and the mean value was used for analysis. The Modic changes were characterized on magnetic resonance imaging, Type I changes consist of reduced signal intensity (SI) in the vertebral end plates on T1- and increased SI on T2-weighted sequences. Type II changes consist of increased SI on T1- and either increased SI or isointensity on T2-weighted sequences. Type III changes consist of reduced SI on both T1- and T2-weighted sequences due to subchondral sclerosis (Figure 4).

Data were analyzed using Statistical Product and Service Solutions software (version 13; SPSS, Chicago, IL, USA). 


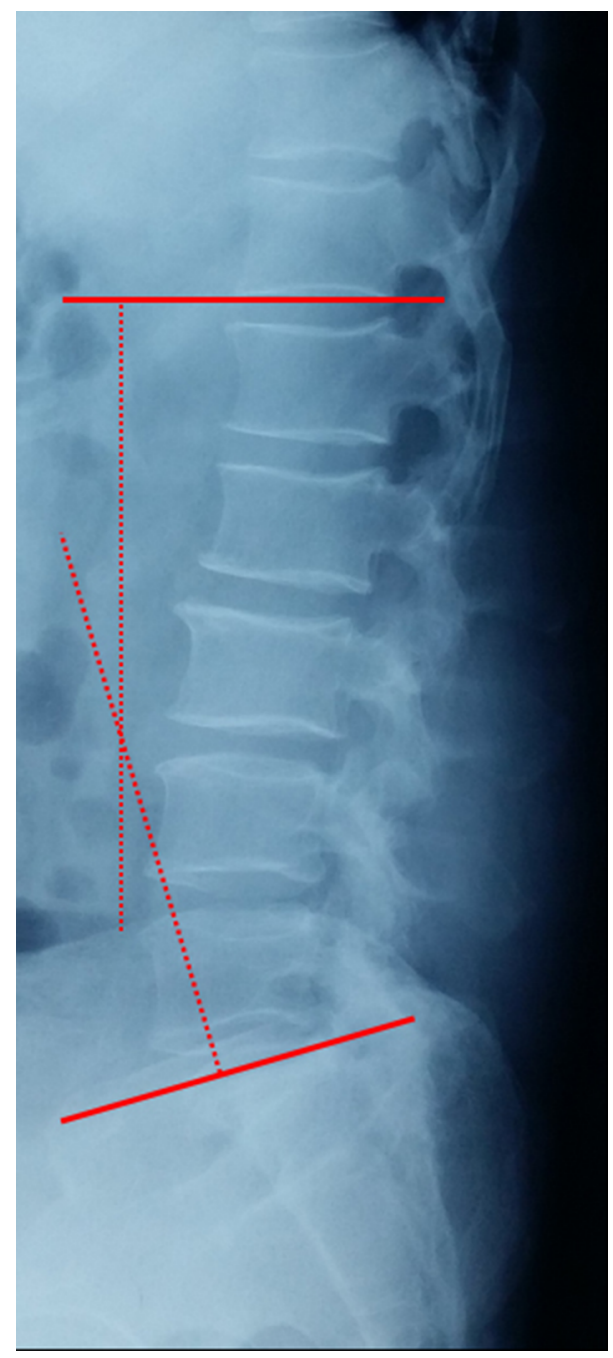

Figure I Lumbar lordosis was measured from TI 2 inferior end plate to SI superior end plate by the Cobb method.

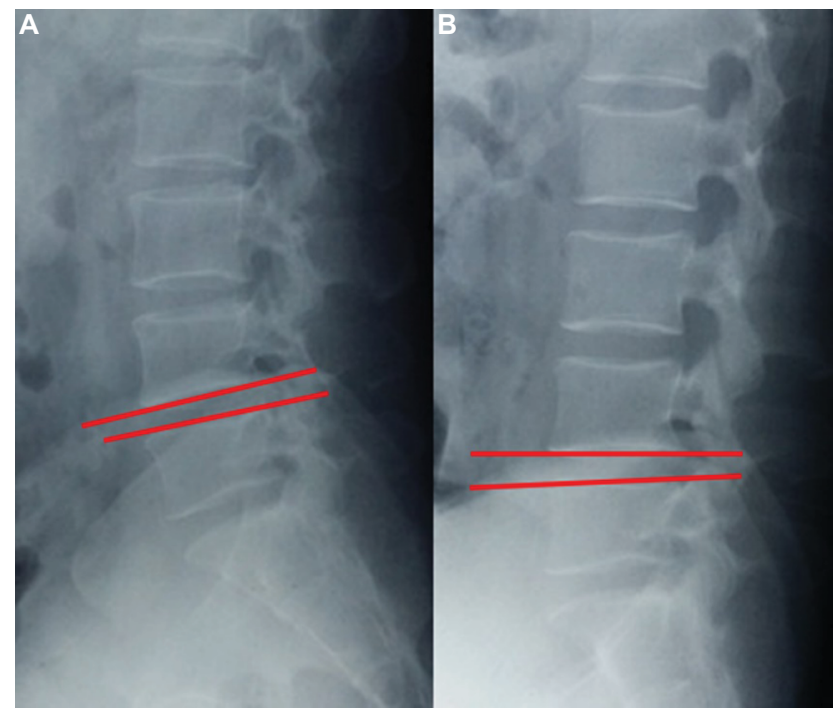

Figure $\mathbf{2}$ Lumbar mobility was calculated as the difference of $L L$ on flexion $(\mathbf{A})$ and extension (B) lateral radiographs.

Abbreviation: LL, lumbar lordosis.
Continuous variables were measured as mean \pm standard deviation, and categorical variables were expressed as frequency or percentages. An independent $t$-test was used to analyze the difference in continuous variables between two groups. $\chi^{2}$ analysis and Fisher's exact test were used to examine the differences among categorical variables. Variables with $p$ values $<0.05$ in the univariate analyses, as well as a number of variables selected by experts, were entered into a multivariate logistic regression model. For each variable, we computed the odds ratio (OR) with its $95 \% \mathrm{CI}$.

Patients were classified as having persistent back pain (PLBP) if NRS scores were $>50$ at all postoperative follow-up time points (3, 6, and 12 months). According to the occurrence of PLBP, patients were divided into two groups: PLBP group and non (N)-PLBP group. To investigate risk values for PLBP, the following three categorized factors were analyzed statistically. Patient characteristics: age, gender, body mass index (BMI), preoperative back pain (NRS), comorbidity (hypertension, diabetes, rheumatism, and heart disease), smoking (yes vs. no), and drinking (yes vs. no). Surgical variables: surgical strategy (TLIF vs. PLIF), surgical segment, the number of fusion levels, surgery time, blood loss, and size of incision. Radiographic parameters: preoperative LL, correction of LL at immediate postoperation, Modic changes, and preoperative paraspinal muscle degeneration (FIR).

\section{Statistical analysis}

PLBP was detected in 16 of 221 patients (7.2\%) and were enrolled into the PLBP group. The mean NRS was $74.3 \pm$ 10.2 at 3-month follow-up, $68.7 \pm 5.3$ at 6-month follow-up, and 58.6 \pm 3.8 at 12-month follow-up. Most of the patients failed to the pain medication and physical therapy. A total of 205 patients $(93.8 \%)$, whose NRS evaluation was $<50$ at any follow-up time point (3 months, 6 months, and 12 months), were enrolled as the N-PLBP group.

\section{Results}

There was no statistically significant difference between the two groups in age at operation, gender, BMI, comorbidity, smoking, and drinking. The preoperative back pain was more severe in the PLBP group than that in the N-PLBP group (Table 1). There was no difference between the two groups in surgery time, blood loss, surgical strategy, number of fusion levels, and the size of incision. Surgery segment of $\mathrm{L}_{5}-\mathrm{S}_{1}$ was more prevalent in the PLBP group than that in the N-PLBP group (Table 2). There was no statistically significant difference between the two groups in preoperative LL, correction of LL, preoperative lumbar mobility, and Modic 


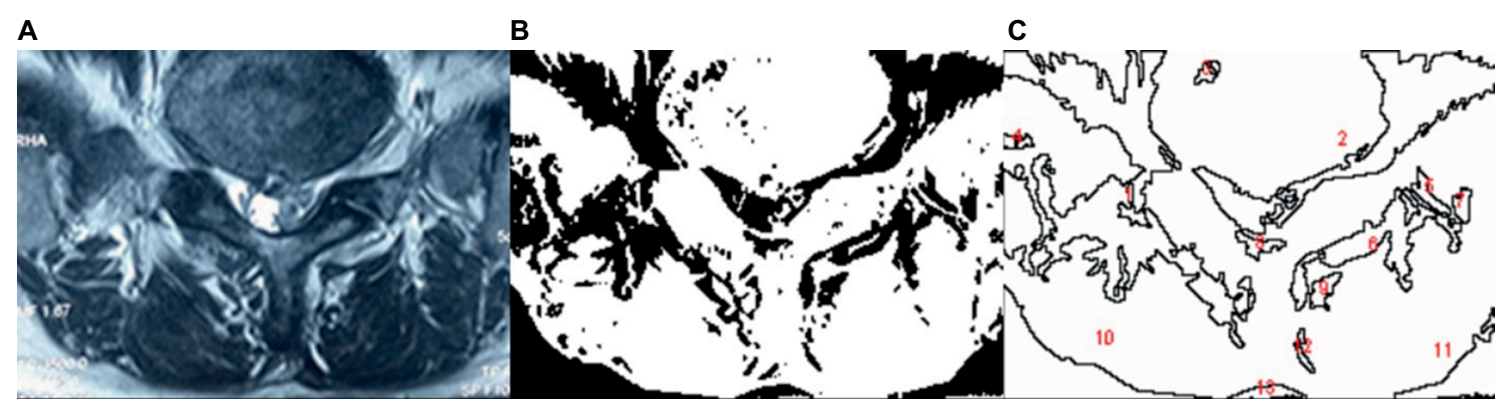

Figure 3 Fatty infiltration rate of paraspinal muscles (multifidus and erector spinae) was calculated by subtracting the muscle without the fat value from the total muscle value. Notes: (A) Is the original image, (B) is the image of fat left, and $(\mathbf{C})$ is the calculation of fat area by software.
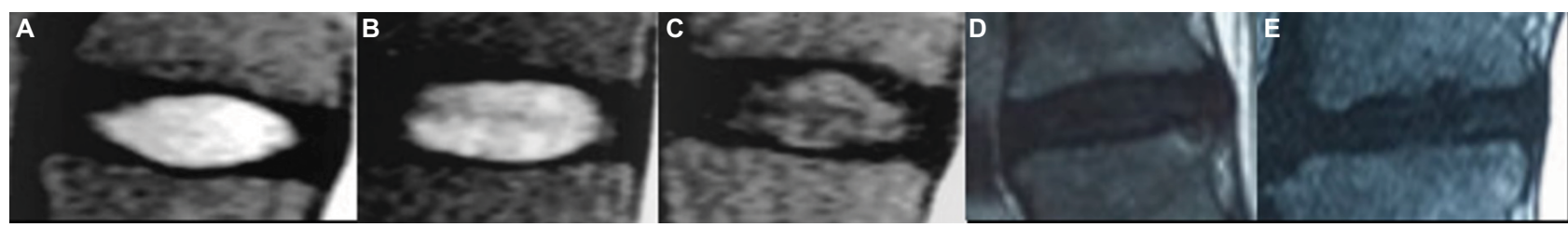

Figure 4 Modic changes were characterized on magnetic resonance imaging.

Notes: Type I changes consist of reduced SI in the vertebral end plates on TI (A)- and increased SI on T2-weighted sequences (B). Type II changes consist of increased SI on TI (C)- and either increased SI or isointensity on T2-weighted sequences (D). Type III changes consist of reduced SI on both TI- and T2-weighted sequences due to subchondral sclerosis (E).

Abbreviation: SI, signal intensity.

Table I Comparison of patient characteristics between PLBP group and N-PLBP group

\begin{tabular}{llll}
\hline Variables & $\begin{array}{l}\text { PLBP group } \\
(\mathbf{n}=16)\end{array}$ & $\begin{array}{l}\text { N-PLBP group } \\
(\mathbf{n = 2 0 5})\end{array}$ & -value \\
\hline Mean age \pm SD (years) & $55.2 \pm 10.1$ & $53.0 \pm 10.8$ & 0.432 \\
Gender (F/M) & $10 / 6$ & $120 / 85$ & 0.756 \\
BMI & $24.7 \pm 1.9$ & $24.6 \pm 1.8$ & 0.829 \\
Preoperative back pain (NRS) & $29.5 \pm 10.7$ & $22.4 \pm 7.5$ & $<0.001$ \\
Smoking (yes vs. no) & $4 / 12$ & $23 / 182$ & 0.114 \\
Drinking (yes vs. no) & $2 / 14$ & $12 / 193$ & 0.268 \\
Comorbidity & & & \\
Hypertension & 4 & 36 & - \\
Diabetes & 1 & 17 & \\
Rheumatism & 0 & 2 & \\
Heart disease & 2 & 11 & \\
\hline
\end{tabular}

Note: '-' no statistical analysis were done as no need for it in this section. Abbreviations: PLBP, persistent low back pain; N-PLBP, non-persistent low back pain; NRS, numeric rating scale; BMI, body mass index; $F$, female; $M$, male.

changes. The FIR was larger in the PLBP group than that in the N-PLBP group (Table 3).

All the three categorized factors, including patient characteristics, surgical variables, and radiographic parameters, were entered into the model, and the multivariate logistic regression model revealed that preoperative back pain (NRS $>35$ ), surgery segment at $\mathrm{L}_{5}-\mathrm{S}_{1}$, and large FIR $>15 \%$ were independently associated with PLBP (Table 4).

\section{Discussion}

In the present study, 16 of 221 patients (7.2\%) experienced persistent back pain, with NRS scores $>50$ at all postoperative follow-up time points. We found that preoperative back
Table 2 Comparison of surgical variables between PLBP group and N-PLBP group

\begin{tabular}{llll}
\hline Variables & $\begin{array}{l}\text { PLBP group } \\
(\mathbf{n = 1 6})\end{array}$ & $\begin{array}{l}\text { N-PLBP group } \\
(\mathbf{n = 2 0 5})\end{array}$ & p-value \\
\hline $\begin{array}{l}\text { Surgical strategy } \\
\text { TLIF }\end{array}$ & 5 & 73 & \\
PLIF & $\mathrm{II}$ & 132 & 0.725 \\
Number of fusion levels & & & \\
One & $\mathrm{II}$ & 170 & 0.176 \\
Two & 5 & 35 & \\
Surgery segment & & & \\
$\mathrm{L}_{4}-\mathrm{L}_{5}$ & 0 & 107 & $0.00 \mathrm{I}$ \\
$\mathrm{L}_{5}-\mathrm{S}_{\text {I }}$ & $\mathrm{II}$ & 63 & \\
$\mathrm{~L}_{4}-\mathrm{S}_{\text {I }}$ & 5 & 35 & \\
Surgery time $(\mathrm{min})$ & $\mathrm{I} 34.4 \pm \mathrm{II} .6$ & $130.5 \pm \mathrm{II} .3$ & 0.189 \\
Bleeding $(\mathrm{mL})$ & $573.1 \pm 106.1$ & $552.3 \pm 99.8$ & 0.458 \\
Size of incision $(\mathrm{cm})$ & $10.3 \pm 2.0$ & $11.0 \pm 2.5$ & 0.229 \\
\hline
\end{tabular}

Abbreviations: PLBP, persistent low back pain; N-PLBP, non-persistent low back pain; PLIF, posterior lumbar interbody fusion; TLIF, transforaminal lumbar interbody fusion.

Table 3 Comparison of radiographic parameter between PLBP group and N-PLBP group

\begin{tabular}{llll}
\hline Variables & \multicolumn{3}{c}{ PLBP group N-PLBP group $\mathbf{p}$-value } \\
& $(\mathbf{n = 1 6 )}$ & $\mathbf{( n = 2 0 5 )}$ & \\
\hline Preoperative lumbar lordosis & $26.2 \pm 6.7$ & $24.6 \pm 2.9$ & 0.070 \\
Correction of lumbar lordosis & $2.4 \pm 1.0$ & $1.9 \pm 0.9$ & 0.079 \\
Modic changes & $2 / 14$ & $32 / 172$ & 0.734 \\
Preoperative paraspinal muscle & $15.6 \pm 6.6$ & $11.5 \pm 7.3$ & 0.031 \\
degeneration (FIR) & & &
\end{tabular}

Abbreviations: PLBP, persistent low back pain; N-PLBP, non-persistent low back pain; FIR, fatty infiltration rate.

pain $(\mathrm{NRS}>35)$, surgery segment at $\mathrm{L}_{5}-\mathrm{S}_{1}$, and large FIR > $15 \%$ were significantly and independently associated with the persistent back pain and can be assessed before surgery. 
Table 4 Risk factors of PLBP, identified by logistic regression analysis

\begin{tabular}{lll}
\hline Risk factors & Odds ratio $(95 \% \mathbf{C I})$ & $p$-value \\
\hline Age & $0.788(0.264-2.357)$ & 0.670 \\
Gender & $1.745(0.561-5.422)$ & 0.336 \\
BMI & $0.453(0.139-1.48 I)$ & 0.190 \\
Preoperative back pain & $5.548(1.443-21.330)$ & 0.013 \\
Surgical strategy & $0.905(0.294-2.787)$ & 0.862 \\
Surgical segment & $3.891(1.239-15.773)$ & 0.025 \\
Number of fusion levels & $0.906(0.292-2.81 \mathrm{I})$ & 0.864 \\
Surgery time & $0.584(0.180-1.894)$ & 0.370 \\
Blood loss & $0.779(0.255-2.377)$ & 0.661 \\
Size of incision & $1.217(0.378-3.919)$ & 0.743 \\
Preoperative lumbar lordosis & $2.315(0.723-7.416)$ & 0.157 \\
Correction of lumbar lordosis & $1.672(0.524-5.332)$ & 0.385 \\
Preoperative lumbar mobility & $2.765(0.783-9.757)$ & 0.114 \\
Modic changes & $\mathrm{I} .157(0.903-1.483)$ & 0.250 \\
Preoperative FIR & $3.768(1.226-13.983)$ & 0.029 \\
\hline
\end{tabular}

Abbreviations: PLBP, persistent low back pain; $\mathrm{Cl}$ confidence interval; BMI, body mass index; FIR, fatty infiltration rate.

These results were not confounded by other variables that potentially affect postoperative PLBP.

Previous studies have demonstrated that the preoperative pain severity closely associated with the occurrence of postoperative back pain both at short- and long-term postoperation. Papaioannou et al. ${ }^{15}$ proved that preoperative pain catastrophizing was a unique predictor of acute postoperative back pain at early stage and the analgesic use followed lumbar fusion operation. Abbott et al. ${ }^{16}$ found that the preoperative pain catastrophizing predicted the back pain intensity and disability 2-3 years after lumbar fusion operation. In the present study, most of the patients received posterior decompression and instrumented fusion for lumbar disk herniation, lower limb symptoms derived from nerve root compression is the main surgical indication, instead of back pain. The major source of preoperative back pain may be disk degeneration, intervertebral instability, vertebral osteoporosis, facet joint degeneration, end plate degeneration (Modic changes), and paraspinal muscle degeneration. The instrumentation in both TLIF and PLIF could decrease the intervertebral instability and increase the fusion rate, but without effect on the disk, facet joint, and paraspinal muscle degeneration, especially for patients with osteoporosis, as back pain caused by osteoporosis is hard to be managed. Moreover, the surgical exposure and intraoperative use of muscle retractor may damage the paraspinal muscles inevitably, and the postoperative muscle scar could induce or increase the back pain. Degeneration of spinal structures is progressive and irreversible and can be influenced by each other. For instance, the end plate degeneration may influence the blood supply to the intervertebral disk, then accelerate the disk degeneration, and result in the PLBP. The intervertebral disk and bilateral facet joint play an important role in the movement of the spinal functional unit (SFU); facet joint degeneration may increase the intervertebral instability, and vice versa. If the exact cause of low back pain is not identified before surgery and not managed successfully, the symptoms will continue to be the persistent back pain postoperatively.

The lumbosacral junction is the most important region in the vertebral column in terms of weight bearing and mobility, and it is widely accepted that mechanical disorders of this region could cause low back pain. ${ }^{17-20}$ In the present study, we found that surgery segment at $\mathrm{L}_{5}-\mathrm{S}_{1}$ was an independent risk factor of postoperative persistent back pain, even at 12-month follow-up. Our result is partly consistent with the previous studies and adds knowledge for the association between lumbosacral junction disorders and persistent back pain. There are three possible explanations for the association. First, the $\mathrm{L}_{4}-\mathrm{L}_{5}$ and $\mathrm{L}_{5}-\mathrm{S}_{1}$ disk levels account for $\sim 2 / 3$ mobility and lordotic curvature of the whole lumbar spine, indicating that both the $\mathrm{L}_{4}-\mathrm{L}_{5}$ and $\mathrm{L}_{5}-\mathrm{S}_{1}$ facet joints are "deep" when patients are in prone position, and a large number of paraspinal muscles are distributed here. Exposure of the pedicle screw insertion point is hard due to the anatomical characteristics, which require a larger range of surgical exposure. Second, the angle of $\mathrm{L}_{5}$ and $\mathrm{S}_{1}$ pedicle screw insertion differs from other lumbar segments, as the pedicle screw entering angle at lumbosacral junction is more outward-inclined, which also needs a larger range of surgical exposure. The long incisions, extensive detachment of muscle from the spinal processes, and subsequently prolonged wide retraction can result in ischemic necrosis and denervation of the paraspinal muscles. ${ }^{21,22}$ Third, stress concentration and mobility increase at $\mathrm{L}_{4}-\mathrm{L}_{5}$ may occur followed by $\mathrm{L}_{5}-\mathrm{S}_{1}$ decompression and instrumented fusion, and the occurrence of adjacent segment degeneration or disease will inevitably lead to back pain and/or lower limb symptom. For the degenerated lumbar intervertebral disk adjacent to the fusion segment, the inherent decreased function and the biomechanical alterations make it more vulnerable to experience degeneration after instrumented fusion surgery. ${ }^{23}$

Paraspinal muscle degeneration, characterized as muscular atrophy or high FIR in imaging findings, has been proved to be closely associated with low back pain in previous studies. Kader et al. ${ }^{24}$ analyzed the lumbar MRI data of patients with chronic low back pain and found that $80 \%$ of them presented multifidus muscle atrophy. Parkkola et al. ${ }^{25}$ noted that the psoas muscles and the paraspinal muscles were smaller in patients with chronic low back pain when compared to 
the healthy control adults. Lee et $\mathrm{al}^{26}$ demonstrated that the CSA of erector spinae muscles at the lower lumbar level and the proportion of erector spinae muscle to lumbar muscles at the lower margin of $\mathrm{L}_{5}$ vertebrae can be considered to be prognostic factors of chronic low back pain; they also suggested that there is an association between the development of the acute back pain into a chronic one and the erector spinae muscles. There are two mechanisms that cause the atrophy and fatty infiltration of the paraspinal muscles: denervation and disuse. Dangaria and Naesh ${ }^{27}$ observed that patients with ipsilateral disk herniation showed reduced CSA of the ipsilateral psoas muscles. In a study that examined the histochemical changes in the multifidus muscle in patients with lumbar disk herniation, the atrophy of muscle fiber was only observed where there was nerve root impairment. ${ }^{28}$ No matter which type of mechanism, if paraspinal muscle atrophy is present, the atrophy regeneration is hard. Barker et al. ${ }^{29}$ noted that the multifidus muscle atrophy occurs where nerve root compression or irritation occurs, with the degree of atrophy being positively dependent on the duration and severity of the disease. Kader et al. ${ }^{24}$ proposed that lumbar dorsal ramus syndrome causes multifidus muscle atrophy of patients with low back pain, which will trigger a self-sustained vicious cycle that promotes atrophy. As mentioned earlier, the approachrelated morbidity resulting from iatrogenic muscle and soft tissue injury will inevitably aggravate muscle atrophy and finally lead to the persistent back pain postoperatively. This view is supported by a study of Fan et al, ${ }^{30}$ who concluded that the minimally invasive approach caused less change in multifidus, less postoperative back pain and functional disability than conventional open approach, the muscle damage during surgery was significantly correlated with long-term multifidus muscle atrophy and fatty infiltration.

There are several potential limitations in this study. First, the number of patients is relatively small, and the study may be underpowered to detect the significance of some risk factors. Second, the study was conducted retrospectively by case selection and was not randomized and controlled. Even with these issues in this study, we find that preoperative back pain (NRS $>35$ ), surgery segment of $\mathrm{L}_{5}-\mathrm{S}_{1}$, and large FIR $>15 \%$ are risk factors of the persistent back pain. Patients with preoperative back pain or severe paraspinal muscle degeneration should be fully informed the risk of persistent back pain. While for spinal surgeons, posterior decompression and instrumented fusion at the $\mathrm{L}_{5}-\mathrm{S}_{1}$ level should be paid more attention to protect the paraspinal muscle, especially in the procedure of surgical exposure and intermittent use of muscle retractor.

\section{Disclosure}

The authors report no conflicts of interest in this work.

\section{References}

1. Lequin MB, Verbaan D, Bouma GJ. Posterior lumbar interbody fusion with stand-alone Trabecular Metal cages for repeatedly recurrent lumbar disc herniation and back pain. J Neurosurg Spine. 2014;20(6):617-622.

2. Cao P, Chen Z, Zheng Y, et al. Comparison of simple discectomy and instrumented posterior lumbar interbody fusion for treatment of lumbar disc herniation combined with Modic endplate changes. Chin Med $J$ (Engl). 2014;127(15):2789-2794.

3. Satoh I, Yonenobu K, Hosono N, Ohwada T, Fuji T, Yoshikawa H. Indication of posterior lumbar interbody fusion for lumbar disc herniation. J Spinal Disord Tech. 2006;19(2):104-108.

4. Kim KH, Park JY, Chin DK. Fusion criteria for posterior lumbar interbody fusion with intervertebral cages: the significance of traction spur. J Korean Neurosurg Soc. 2009;46(4):328-332.

5. Fuji T, Oda T, Kato Y, Fujita S, Tanaka M. Posterior lumbar interbody fusion using titanium cylindrical threaded cages: is optimal interbody fusion possible without other instrumentation? J Orthop Sci. 2003; 8(2):142-147.

6. Rihn JA, Patel R, Makda J, et al. Complications associated with singlelevel transforaminal lumbar interbody fusion. Spine J. 2009;9(8): 623-629.

7. Baeesa SS, Medrano BG, Noriega DC. Long-term outcomes of posterior lumbar interbody fusion using stand-alone ray threaded cage for degenerative disk disease: a 20-year follow-up. Asian Spine J. 2016; 10(6): 1100-1105.

8. Abd El-Kader Hel-B. Transforaminal lumbar interbody fusion for management of recurrent lumbar disc herniation. Asian Spine J. 2016; 10(1):52-58.

9. Parker SL, Mendenhall SK, Godil SS, et al. Incidence of low back pain after lumbar discectomy for herniated disc and its effect on patientreported outcomes. Clin Orthop Relat Res. 2015;473(6):1988-1999.

10. Clarke AM, Stillwell S, Paterson ME, Getty CJ. Role of the surgical position in the development of postoperative low back pain. $J$ Spinal Disord. 1993;6(3):238-241.

11. Gu J, Guan F, Zhu L, et al. Risk factors of postoperative low back pain for lumbar spine disease. World Neurosurg. 2016;94:248-254.

12. Carragee EJ, Spinnickie AO, Alamin TF, Paragioudakis S. A prospective controlled study of limited versus subtotal posterior discectomy: short-term outcomes in patients with herniated lumbar intervertebral discs and large posterior anular defect. Spine (Phila Pa 1976). 2006;31(6):653-657.

13. Schoeggl A, Maier H, Saringer W, Reddy M, Matula C. Outcome after chronic sciatica as the only reason for lumbar microdiscectomy. J Spinal Disord Tech. 2002;15(5):415-419.

14. AlBedah A, Khalil M, Elolemy A, et al. The use of wet cupping for persistent nonspecific low back pain: randomized controlled clinical trial. J Altern Complement Med. 2015;21(8):504-508.

15. Papaioannou M, Skapinakis P, Damigos D, Mavreas V, Broumas G, Palgimesi A. The role of catastrophizing in the prediction of postoperative pain. Pain Med. 2009;10(8):1452-1459.

16. Abbott AD, Tyni-Lenne R, Hedlund R. Leg pain and psychological variables predict outcome 2-3 years after lumbar fusion surgery. Eur Spine J. 2011;20(10):1626-1634.

17. Evcik D, Yücel A. Lumbar lordosis in acute and chronic low back pain patients. Rheumatol Int. 2003;23(4):163-165.

18. Jackson RP, McManus AC. Radiographic analysis of sagittal plane alignment and balance in standing volunteers and patients with low back pain matched for age, sex and size. A prospective controlled clinical study. Spine (Phila Pa 1976). 1994;19(14):1611-1618.

19. Amonoo-Kuofi HS. Changes in the lumbosacral angle, sacral inclination and the curvature of the lumbar spine during aging. Acta Anat (Basel). 1992;145(4):373-377. 
20. Nakipoğlu GF, Karagöz A, Ozgirgin N. The biomechanics of the lumbosacral region in acute and chronic low back pain patients. Pain Physician. 2008;11(4):505-511.

21. Sihvonen T, Herno A, Paljarvi L, Airaksinen O, Partanen J, Tapaninaho A. Local denervation atrophy of paraspinal muscles in postoperative failed back syndrome. Spine (Phila Pa 1976). 1993;18(5):575-581.

22. Taylor H, McGregor AH, Medhi-Zadeh S, et al. The impact of selfretaining retractors on the paraspinal muscles during posterior spinal surgery. Spine (Phila Pa 1976). 2002;27(24):2758-2762.

23. Kim HJ, Kang KT, Chun HJ, Lee CK, Chang BS, Yeom JS. The influence of intrinsic disc degeneration of the adjacent segments on its stress distribution after one-level lumbar fusion. Eur Spine J. 2015;24(4):827-837.

24. Kader DF, Wardlaw D, Smith FW. Correlation between the MRI changes in the lumbar multifidus muscles and leg pain. Clin Radiol. 2000;55(2):145-149.

25. Parkkola R, Rytokoski U, Kormano M. Magnetic resonance imaging of the discs and trunk muscles in patients with chronic low back pain and healthy control subjects. Spine (Phila Pa 1976). 1993;18(7):830-836.
26. Lee HI, Song J, Lee HS, Kang JY, Kim M, Ryu JS. Association between cross-sectional areas of lumbar muscles on magnetic resonance imaging and chronicity of low back pain. Ann Rehabil Med. 2011;35(6): 852-859.

27. Dangaria TR, Naesh O. Changes in cross-sectional area of psoas major muscle in unilateral sciatica caused by disc herniation. Spine (Phila Pa 1976). 1998;23(8):928-931.

28. Yoshihara K, Shirai Y, Nakayama Y, Uesaka S. Histochemical changes in the multifi dus muscle in patients with lumbar intervertebral disc herniation. Spine (Phila Pa 1976). 2001;26(6):622-626.

29. Barker KL, Shamley DR, Jackson D. Changes in the cross-sectional area of multifidus and psoas in patients with unilateral back pain: the relationship to pain and disability. Spine (Phila Pa 1976). 2004;29(22):E515-E519.

30. Fan S, Hu Z, Zhao F, Zhao X, Huang Y, Fang X. Multifidus muscle changes and clinical effects of one-level posterior lumbar interbody fusion: minimally invasive procedure versus conventional open approach. Eur Spine J. 2010;19(2):316-324.
Journal of Pain Research

\section{Publish your work in this journal}

The Journal of Pain Research is an international, peer reviewed, open access, online journal that welcomes laboratory and clinical findings in the fields of pain research and the prevention and management of pain. Original research, reviews, symposium reports, hypothesis formation and commentaries are all considered for publication.

\section{Dovepress}

The manuscript management system is completely online and includes a very quick and fair peer-review system, which is all easy to use. Visit http://www.dovepress.com/testimonials.php to read real quotes from published authors. 